\title{
Child mortality in South Africa: Fewer deaths, but better data are needed
}

\author{
L J Bamford, ${ }^{1}$ FCPaed (SA), DrPH; N H McKerrow, ${ }^{2}$ FCPaed (SA), MMed (Paed); P Barron, ${ }^{3}$ BCom, FFCH (SA); Y Aung, ${ }^{4} \mathrm{MBBS}, \mathrm{MPH}$ \\ ${ }^{1}$ National Department of Health, Pretoria, South Africa \\ ${ }^{2}$ KwaZulu-Natal Department of Health; and Department of Paediatrics and Child Health, University of KwaZulu-Natal, Durban, South Africa \\ ${ }^{3}$ School of Public Health, University of the Witwatersrand, Johannesburg, South Africa \\ ${ }^{4}$ UNICEF, Pretoria, South Africa
}

Corresponding author: L J Bamford (lesley.bamford@health.gov.za)

\begin{abstract}
South Africa is committed to reducing under-5 mortality rates in line with the Sustainable Development Goal (SDG) targets. Policymakers and healthcare service managers require accurate and complete data on the number and causes of child deaths to plan and monitor healthcare service delivery and health outcomes. This study aimed to review nationally representative data on under-5 mortality and the cause of deaths among children under 5 years of age. We also reviewed systems that are currently used for generating these data. Child mortality has declined substantially in the past decade. Under- 5 mortality in 2015 is estimated at 37 - 40 deaths per 1000 live births, with an estimated infant mortality rate of 27 - 33 deaths per 1000 live births. Approximately one-third of under- 5 deaths occur during the newborn period, while diarrhoea, pneumonia and HIV infection remain the most important causes of death outside of the newborn period. The proportion of deaths owing to non-natural causes, congenital disorders and non-communicable diseases has increased.

However, many discrepancies in data collected through different systems are noted, especially at the sub-national level. There is a need to improve the completeness and accuracy of existing data systems and to strengthen reconciliation and triangulation of data.
\end{abstract}

S Afr Med J 2018;108(3 Suppl 1):S25-S32. DOI:10.7196/SAMJ.2018.v108i3.12779

Reducing child mortality represents an important health sector and societal goal at a global $^{[1]}$ and national level. ${ }^{[2]}$ Sustainable Development Goal (SDG) 3 calls for an 'end to preventable deaths of newborns and children under five years', which demands a reduction of under-5 mortality to $<25$ per 1000 live births and the neonatal mortality rate to be $<12$ per 1000 live births in every country by 2030 (SDG indicators 3.2.1 and 3.2.2, respectively). ${ }^{[3]}$

Policymakers and healthcare service managers require accurate and complete data on the number and causes of child deaths to plan and monitor child health and child healthcare service delivery. ${ }^{[4,5]}$ The preferred source of data for the monitoring of deaths and under-5 mortality rates is a civil or vital registration (VR) system that records births and deaths on a continuous basis, collects information as events occur and covers the entire population ${ }^{[6]}$ If registration coverage is complete and the systems function efficiently, the resulting child mortality estimates will be accurate, timely and available at national, sub-national and local levels. However, many countries, including South Africa (SA), remain without viable or fully functioning VR systems that accurately record all births and deaths. ${ }^{[7,8]}$

The study aimed to review nationally representative data on the levels and trends of under- 5 mortality rates, the causes of death among children under 5 years of age in SA, and current systems that report on child mortality on a national and sub-national level to identify gaps, and to make recommendations for improving the availability of complete, accurate and timely information on child deaths.

\section{Methods}

The following major national systems that present data on child deaths were reviewed and the key features of the systems were summarised and compared: the Vital Registration (VR) System of Statistics South
Africa (StatsSA); the Rapid Mortality Surveillance (RMS) of the South African Medical Research Council (SAMRC), which is used by the National Department of Health (NDoH) to monitor trends in child mortality; ${ }^{[9]}$ the District Health Information System (DHIS) of the NDoH; the United Nations (UN) Inter-agency Group for Child Mortality Estimation; the South African Demographic and Health Survey (SADHS) of StatsSA; and the population census of StatsSA. The currently available national and sub-national estimates of under5 mortality and causes of death in these systems were reviewed and compared. Where available, published data were used, while DHIS and VR data were extracted directly from the relevant databases. The comparisons allowed the authors to identify gaps and discrepancies between the different data systems, and these discrepancies are also described.

\section{Results}

The information systems and surveys that collect nationally representative data, or provide national estimates, on child deaths are summarised in Table 1. A brief description of each system/ survey is provided alongside its strengths and limitations. Each of the systems estimates or calculates child mortality numbers and rates using different data sources, different methods and different interpretations; taken together they provide an overall perspective on child mortality.

National estimates of under-5 deaths and mortality rates Under-5 mortality rates in SA are shown in Fig. 1. The HIV epidemic during the late 1990s and early 2000s, with a peak in 2003, led to an increase in infant and child mortality. However, infant and under5 mortality rates have declined during the past decade. The UN figures show that under-5 mortality peaked in 2003 (at 78.1 per 


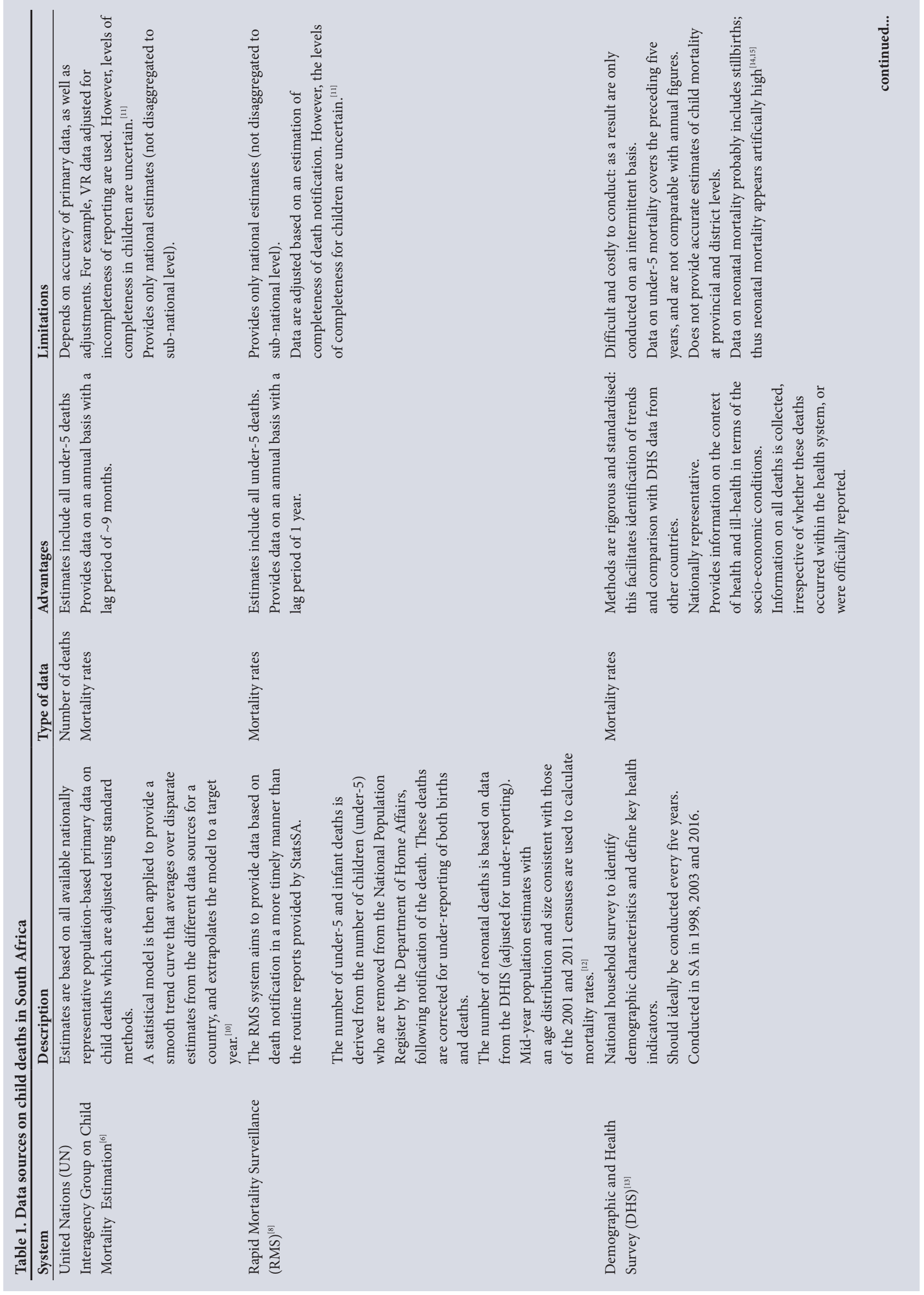




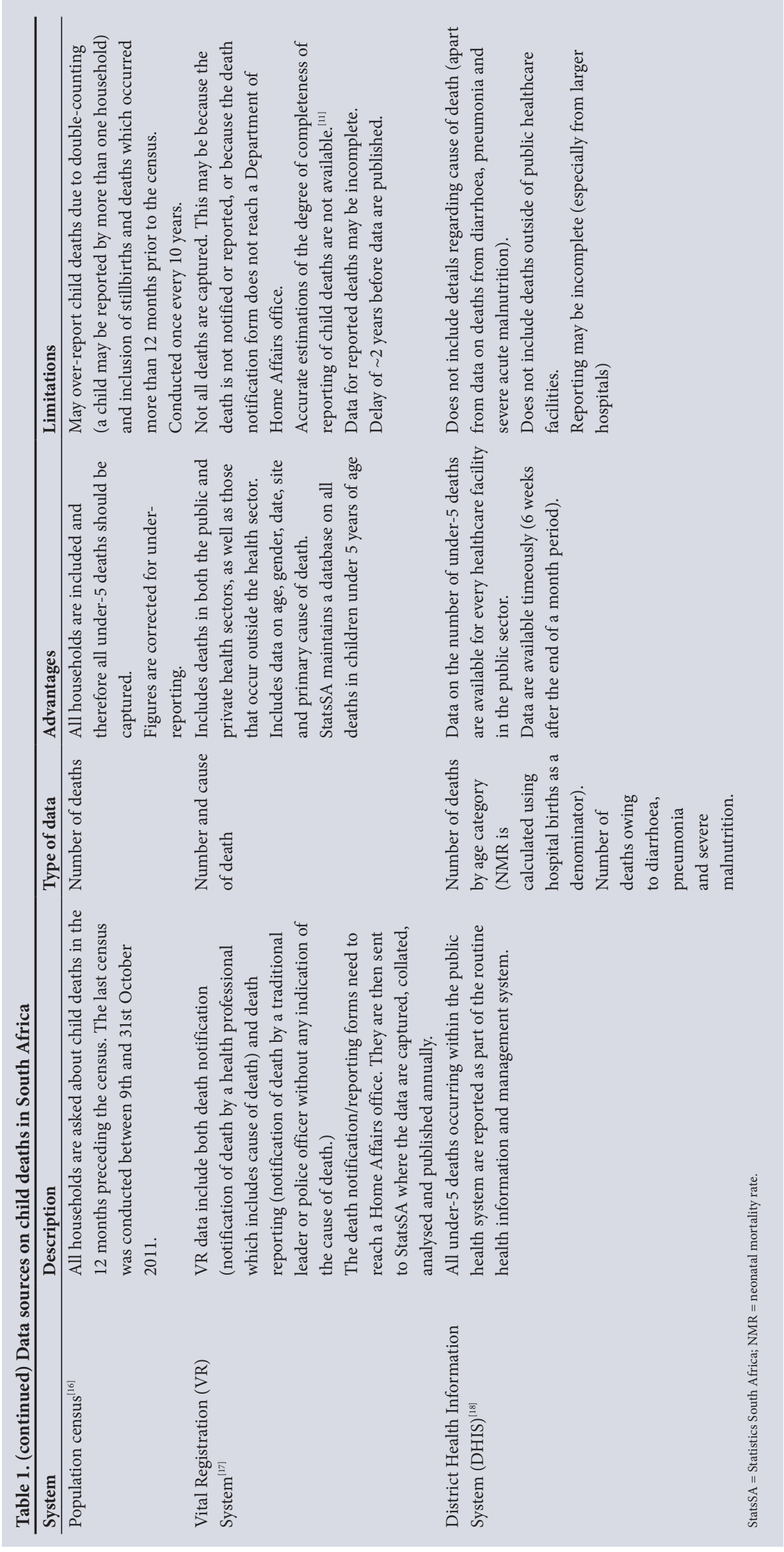

1000 live births) before declining steadily to 40.5 per 1000 live births in 2015. The RMS figures suggest a more rapid decline from 2008 to 2010, followed by a much slower decline to 37 per 1000 live births in 2015. UN data estimate that the total number of under- 5 deaths fell from 63994 in 1990 to 41930 in 2015. ${ }^{[19]}$ The infant mortality rate followed a similar pattern as the under-5 mortality rate, with the UN reporting an infant mortality rate of 33.6 per 1000 live births in 2015, while the RMS reported a figure of 27 per 1000 live births. The 2016 SADHS reported an under-5 mortality rate of 42 per 1000 and an infant mortality rate of 35 per 1000 in the 5 years preceding the survey ${ }^{[13]}$

While newborn deaths are discussed in more detail elsewhere in this special issue, ${ }^{[20]}$ the contribution of neonatal mortality to the overall under-5 mortality should be noted. A number of sources, i.e. UN estimates, RMS and DHIS reported neonatal mortality rates of $\sim 11-12$ per 1000 live births in 2015. In contrast, the 2016 SADHS reported a neonatal mortality rate of 21 per 1000 . UN estimates and RMS data suggest that the proportion of under-5 deaths that occur in the neonatal period has increased in the past decade: UN estimates show an increase from $18 \%$ in 2005 to $27 \%$ in 2015 and RMS estimates suggest a similar pattern. In contrast, SADHS data suggest that newborn deaths accounted for $50 \%$ of under- 5 deaths. ${ }^{\left[{ }^{[3]}\right]}$ This figure is more closely aligned with the global estimate that $45 \%$ of under- 5 deaths occur during the newborn period, ${ }^{[21]}$ but may be artificially high owing to misclassification of stillbirths as neonatal death, which has been shown to occur during such surveys in other countries. ${ }^{[1,15]}$

\section{Total number of under- 5 deaths}

The number of under-5 deaths reported through the VR system decreased from 37908 in 2011 to 31938 in 2015, with a consistent annual decrease in the deaths (Table 2). It should be noted that the VR database is released on an annual basis; the number of deaths in recent years may therefore 


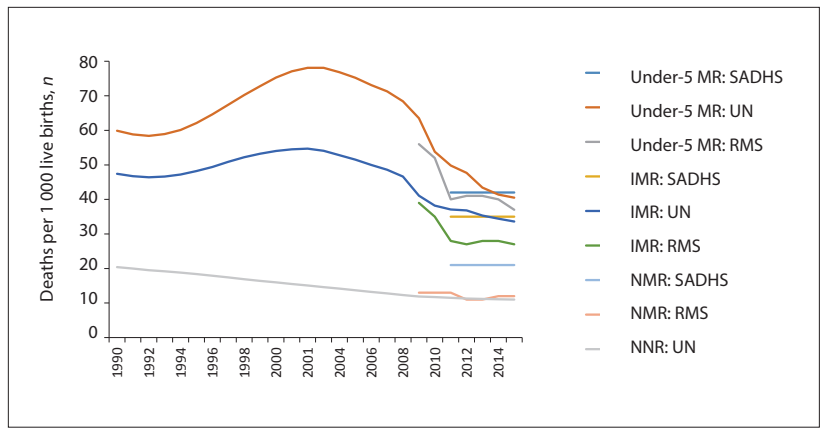

Fig. 1. Child mortality rates in South Africa between 1990 and 2015 based on different sources. ${ }^{[8,13,1,2,21]}(M R=$ mortality rate; $S A D H S=$ South African Demographic and Health Survey; UN = United Nations; RMS = Rapid Mortality Surveillance, $I M R=$ infant mortality rate; $N M R=$ neonatal mortality rate.) through the 2011 census are shown in Table 3. More deaths were reported through the census than through VR for 2011; this is presumed to reflect incomplete VR, although the census may also have over-reported deaths (Table 1). The 54250 child deaths reported in the 2011 census was lower than the UN estimate of 60356 for 2011 (range 50256 - 72 132). ${ }^{[19]}$

The ratio of the difference between the two sources of death numbers ranged from 0.7 (in the Western Cape, which was an exception with more deaths notified in the VR system than were reported in the census) to 2.1 in the Eastern Cape (with more than twice as many deaths in the census compared with the deaths that were notified in the VR system). There were also large differences in KwaZulu-Natal and Mpumalanga, which, like the Eastern Cape, have large underserved rural populations where incomplete VR would be expected. ${ }^{[1,23]}$

Table 2. Number of under-5 deaths by province, VR: $2011-2015$

\begin{tabular}{llllll}
\hline \multicolumn{7}{l}{ Table 2 . Number of under-5 deaths by province, VR: $2011-\mathbf{2 0 1 5}$} & $\mathbf{2 0 1 2}$ & $\mathbf{2 0 1 3}$ & $\mathbf{2 0 1 4}$ & $\mathbf{2 0 1 5}$ \\
\hline Eastern Cape & $\mathbf{2 0 1 1}$ & 3419 & 3242 & 3614 & 3240 \\
Free State & 3678 & 2928 & 2886 & 2671 & 2356 \\
Gauteng & 3754 & 7716 & 7718 & 7699 & 7348 \\
KwaZulu-Natal & 8330 & 7342 & 6506 & 5813 & 5372 \\
Limpopo & 7194 & 5042 & 4707 & 4555 & 4426 \\
Mpumalanga & 4204 & 3096 & 2725 & 2769 & 2597 \\
North West & 2976 & 3300 & 3588 & 3532 & 3171 \\
Northern Cape & 1230 & 1112 & 1295 & 1299 & 1068 \\
Western Cape & 2462 & 2479 & 2280 & 2209 & 2319 \\
South Africa & 37908 & 36915 & 35094 & 34262 & 31938 \\
VR= vital registration. & & & & &
\end{tabular}

Table 3. Comparison of under-5 deaths reported through VR and the population census, by province, $2011^{[16]}$

\begin{tabular}{llll}
\hline & Deaths in VR & Census & Census: VR ratio \\
\hline Eastern Cape & 3687 & 7759 & 2.10 \\
Free State & 3754 & 4015 & 1.07 \\
Gauteng & 8330 & 8591 & 1.03 \\
KwaZulu-Natal & 7194 & 14842 & 2.06 \\
Limpopo & 4204 & 5405 & 1.26 \\
Mpumalanga & 2976 & 5223 & 1.75 \\
North West & 3830 & 4774 & 1.25 \\
Northern Cape & 1222 & 1239 & 1.01 \\
Western Cape & 2462 & 1713 & 0.70 \\
South Africa & 37908 & 54250 & 1.43 \\
VR= vital registration. & & &
\end{tabular}

increase slightly as the database is updated to include deaths that were recently registered.

Similar downward trends in the number of deaths were evident at sub-national (provincial) level, although some inconsistencies are apparent. The number of deaths reported in the Free State and Gauteng declined consistently year-on-year over the 5-year period. However, in the other provinces, although the overall trend was downwards, there were interim increases. Limpopo was the only province in which more deaths were reported in 2015 than in 2011, although there has been a steady decline from 2012 - 2015 .

As noted in Table 1, not all deaths are captured in the VR system, and there is uncertainty regarding the degree of completeness of reporting for young children. Data on under-5 deaths collected

\section{Deaths inside and outside of the health system}

Just over half (50.9\%) of all under-5 deaths in the VR system were reported to have occurred within health facilities in 2015 (Table 4). The lowest proportion was reported in the Eastern Cape (43.5\%) and the highest proportion in the Northern Cape (67.7\%).

The number of VR deaths occurring in health facilities includes deaths that occur in both public and private health facilities. Therefore, the number of these deaths would be expected to be higher than the number of deaths reported through the DHIS, which collects data from public health facilities only. However, in 2015, there were 2963 (18\%) more in-facility deaths reported through the DHIS than through VR (Table 4). This ranged from $28 \%$ fewer deaths in the DHIS in the North West to $126 \%$ more deaths in the DHIS in the Eastern Cape.

\section{Age distribution of under- 5 deaths}

The number and proportion of deaths by age category in 2015 as reported through the VR system and the DHIS are shown in Tables 5 and 6, respectively.

The VR data show that a third of the reported deaths (33.4\%) occurred in the neonatal period and three-quarters (75.8\%) in the first year of life. The Western Cape reported the highest proportion of deaths in the neonatal period (40.1\%) and the first year of life $(82.3 \%)$, while the Eastern Cape reported the lowest proportion of deaths in the neonatal period (20.1\%) and the highest proportion in the latter two age categories ( $47.8 \%$ and $32.2 \%$, respectively).

The DHIS data show that 11979 deaths took place in the neonatal period (first 28 days of life). This was $12 \%$ more than the deaths notified through the VR system, and $37 \%$ more than the number of deaths that were recorded as having occurred in healthcare facilities 
Table 4. In-facility deaths reported to the VR system and the DHIS in 2015

\begin{tabular}{|c|c|c|c|c|}
\hline & VR deaths & $\begin{array}{l}\text { VR deaths occurring in } \\
\text { healthcare facilities, } n(\%)\end{array}$ & DHIS deaths, $n$ & $\begin{array}{l}\text { Ratio of DHIS } \\
\text { deaths: VR deaths in } \\
\text { healthcare facilities }\end{array}$ \\
\hline Eastern Cape & 3240 & $1411(43.5)$ & 3185 & 2.26 \\
\hline Free State & 2356 & $1190(50.5)$ & 867 & 0.73 \\
\hline Gauteng & 7348 & $3839(52.2)$ & 3577 & 0.93 \\
\hline KwaZulu-Natal & 5372 & $3165(58.9)$ & 4351 & 1.37 \\
\hline Limpopo & 4426 & $2021(45.7)$ & 2809 & 1.39 \\
\hline Mpumalanga & 2597 & $1328(51.1)$ & 1545 & 1.16 \\
\hline North West & 3171 & $1532(48.3)$ & 1104 & 0.72 \\
\hline Northern Cape & 1068 & $723(67.7)$ & 570 & 0.79 \\
\hline Western Cape & 2319 & $1054(45.5)$ & 1227 & 1.16 \\
\hline South Africa & 31938 & $16272(50.9)$ & 19235 & 1.18 \\
\hline
\end{tabular}

Table 5. VR under-5 deaths by age category, 2015

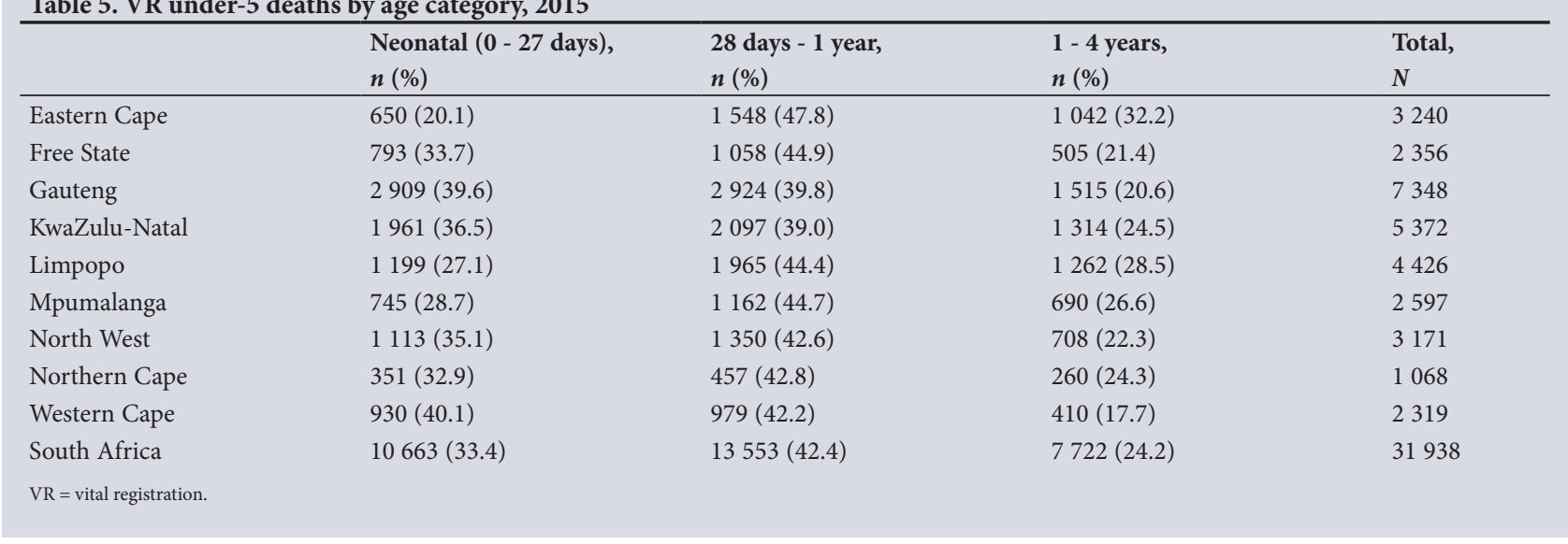

Table 6. DHIS under-5 deaths in public health facilities, 2015

\begin{tabular}{|c|c|c|c|c|}
\hline & $\begin{array}{l}\text { Neonatal (0 - } 28 \text { days), } \\
n(\%)\end{array}$ & $\begin{array}{l}29 \text { days - } 1 \text { year, } \\
n(\%)\end{array}$ & $\begin{array}{l}1 \text { - } 4 \text { years, } \\
n(\%)\end{array}$ & Total, $N$ \\
\hline Eastern Cape & $1897(59.6)$ & $536(16.8)$ & $752(23.6)$ & 3185 \\
\hline Free State & $544(62.7)$ & $127(14.6)$ & $196(22.6)$ & 867 \\
\hline Gauteng & $2600(72.7)$ & 399 (11.2) & $578(16.2)$ & 3577 \\
\hline KwaZulu-Natal & $2546(58.5)$ & $772(17.7)$ & $1033(23.7)$ & 4351 \\
\hline Limpopo & $1723(61.3)$ & $496(17.7)$ & $590(21.0)$ & 2809 \\
\hline Mpumalanga & $821(53.1)$ & $287(18.6)$ & $437(28.3)$ & 1545 \\
\hline North West & $349(61.2)$ & $106(18.6)$ & $115(20.2)$ & 570 \\
\hline Northern Cape & $719(65.1)$ & $174(15.8)$ & $211(19.1)$ & 1104 \\
\hline Western Cape & $780(63.6)$ & $121(9.9)$ & $32626.6)$ & 1227 \\
\hline South Africa & $11979(62.3)$ & 3018 (15.7) & $4238(22.0)$ & 19235 \\
\hline
\end{tabular}

through the VR system (Table 7). As noted above, under-reporting through the VR system is known to occur in rural areas ${ }^{[1,23]}$ and so it is not unexpected that the difference was highest in provinces with large rural populations (Eastern Cape, Limpopo and KwaZulu-Natal). Furthermore, 5673 deaths in infants between 29 days and one year of age were reported as having occurred in healthcare facilities through the VR system (Table 7), while only 3018 deaths among children in this age category were reported through the DHIS (Table 6). This pattern was consistent across all provinces.

\section{Cause of death}

UN and VR cause-of-death data for 2015 are shown in Figs 2 and 3 , respectively. It should be noted that the underlying cause, i.e. the disease that precipitated the change of events that resulted in the death, is used when reporting on the cause of a death. HIV infection is considered to be the cause of death in all cases where this is noted on the death certificate (e.g. as a contributory cause). In contrast, malnutrition is only coded as the cause of death if this is listed as the underlying cause of death on the death certificate. 


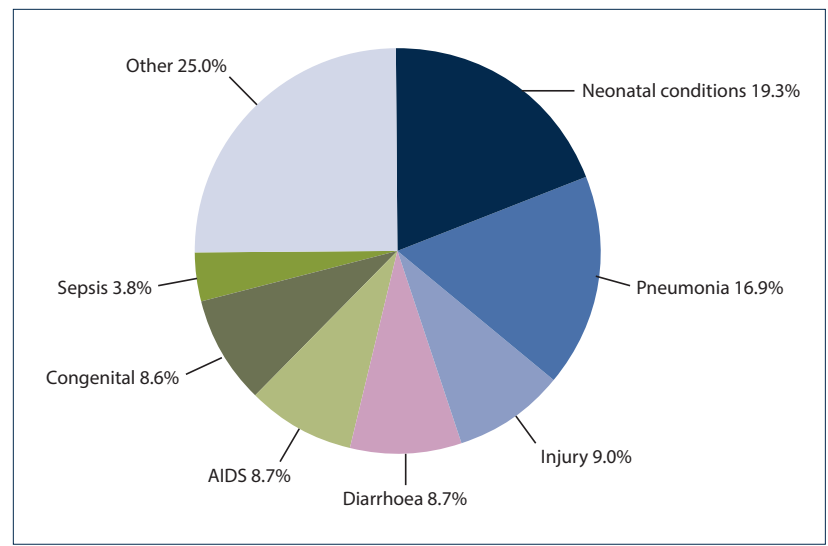

Fig. 2. Cause of under-5 deaths based on 2015 United Nations estimates. ${ }^{[19]}$

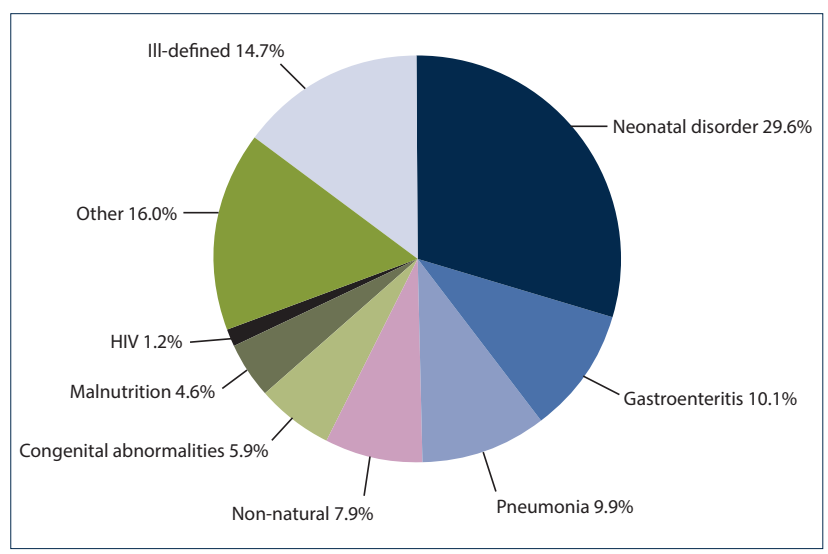

Fig. 3. Cause of under-5 deaths, Vital Registration 2015.
The proportional contribution of the leading causes of death in under5 s for the period 2011 - 2015 is shown in Table 8. There has been an increase in the proportion of deaths owing to neonatal disorders, congenital abnormalities, malnutrition and non-natural deaths (Table 8 ). At the same time there has been a decline in the proportion of deaths attributed to diarrhoea (gastroenteritis) and tuberculosis, and minimal or no change in the proportion of deaths owing to pneumonia and HIV, or where the cause of death is ill-defined (Table 8).

\section{Discussion}

The number of under- 5 deaths, as well as under- 5 mortality rates in SA, have declined in the past decade. Under-5 mortality is estimated at 37 - 40 deaths per 1000 live births for 2015 with an infant mortality rate estimated at 27 - 33 deaths per 1000 live births. Neonatal mortality accounts for approximately one-third of all under-5 deaths.

UN and VR figures both suggest that, outside of the newborn period, pneumonia, diarrhoea and non-natural deaths are the leading causes of death. Declines in the number of deaths and case fatality rates associated with diarrhoea, pneumonia and severe acute malnutrition have contributed substantially to the decline in under-5 mortality. These are discussed in another article in this supplement. ${ }^{[24]}$

It should be noted that VR data underestimate the contribution of HIV infection and malnutrition to under-5 mortality, albeit for different reasons. HIV infection is considered to be the cause of death in all cases were this is noted on the death certificate (e.g. as a contributory cause), and low rates of HIV infection reflect reluctance to record a diagnosis of HIV infection on the death notification form. ${ }^{[25]}$ The UN estimates that $8.7 \%$ of deaths were due to HIV in 2015 is likely to be more accurate, although it remains below the figure of $19 \%$ estimated in the Second Burden of Disease study for 2012. ${ }^{[26]}$

Table 7. Under-5 deaths in health facilities reported through the VR system, 2015

\begin{tabular}{|c|c|c|c|c|}
\hline & Neonatal (0 - 28 days), $n(\%)$ & 29 days - 1 year, $n(\%)$ & $1-4$ years, $n(\%)$ & Total, $N$ \\
\hline Eastern Cape & $438(31.0)$ & $616(43.7)$ & $357(25.3)$ & 1411 \\
\hline Free State & $518(43.5)$ & $459(38.6)$ & $213(17.9)$ & 1190 \\
\hline Gauteng & $2029(52.9)$ & $1247(32.5)$ & $563(14.7)$ & 3839 \\
\hline KwaZulu-Natal & $1521(48.1)$ & $1049(33.1)$ & $595(18.8)$ & 3165 \\
\hline Limpopo & $842(41.7)$ & $692(34.2)$ & $487(24.1)$ & 2021 \\
\hline Mpumalanga & $552(41.6)$ & $508(38.3)$ & $268(20.2)$ & 1328 \\
\hline North West & $252(34.9)$ & $293(40.5)$ & $178(24.6)$ & 723 \\
\hline Northern Cape & $705(46.0)$ & $542(35.4)$ & $285(18.6)$ & 1532 \\
\hline Western Cape & $649(61.6)$ & $267(25.3)$ & $138(13.0)$ & 1054 \\
\hline South Africa & $7512(46.2)$ & $5673(34.9)$ & $3087(19.0)$ & 16272 \\
\hline
\end{tabular}

Table 8. Cause of under-5 deaths as reported through the VR system, 2011 - 2015

\begin{tabular}{|c|c|c|c|c|c|}
\hline Cause & 2011 & 2012 & 2013 & 2014 & 2015 \\
\hline Neonatal disorder & 23.1 & 25.0 & 22.6 & 23.4 & 29.6 \\
\hline Gastroenteritis & 15.0 & 12.3 & 14.6 & 14.0 & 10.1 \\
\hline Pneumonia & 11.0 & 11.2 & 11.2 & 10.8 & 9.9 \\
\hline Non-natural & 6.3 & 7.1 & 7.0 & 7.3 & 7.9 \\
\hline Malnutrition & 3.9 & 3.9 & 3.7 & 4.7 & 4.6 \\
\hline Congenital abnormality & 3.9 & - & 4.2 & 4.9 & 5.9 \\
\hline Tuberculosis & 2.0 & 1.6 & 1.5 & 1.4 & 1.1 \\
\hline $\mathrm{HIV}$ & 1.2 & 1.0 & 1.7 & 1.4 & 1.2 \\
\hline Other & 19.1 & - & 18.6 & 17.9 & 14.9 \\
\hline Ill-defined & 14.5 & - & 14.9 & 14.2 & 14.7 \\
\hline
\end{tabular}


In contrast, malnutrition is only recorded as the cause of death if this is recorded as the underlying cause (and not the immediate or contributory cause) of death. Malnutrition, however, remains an important contributory cause of death as shown by data from child mortality audits which show that almost a third (30.9\%) of children who die are severely malnourished. ${ }^{[27]}$

As expected, as deaths from diarrhoea, pneumonia and SAM decline, deaths from other causes become more prominent. ${ }^{[28]}$ These include deaths during the newborn period, deaths due to non-natural causes as well as deaths associated with congenital abnormalities and non-communicable diseases. Further reductions in child mortality will require ongoing efforts to reduce deaths from traditional causes, as well as a scale-up of interventions aimed at reducing deaths from these emerging causes. Non-natural deaths are particularly challenging, given that most of the interventions required to reduce them lie outside of the health sector.

The high proportion of VR deaths from ill-defined causes reflect both poor completion of death notification forms by health professionals, as well as the fact that death reporting forms (which are completed by community leaders) do not capture cause-of-death information.

A high proportion of child deaths occur outside of healthcare facilities. Just over half $(50.9 \%)$ of the deaths reported through VR occurred outside of the healthcare system, while the DHIS was able to account for $\sim 19000$ out of an estimated 40000 under-5 deaths ${ }^{[19]}$ in 2015. While violence and injury (occurring at home or in the community) account for some of these deaths, a number of recent studies suggest that the majority of caregivers of sick children recognise the need for medical care for their ill child, and seek appropriate care from a variety of providers including the public health sector; however, they are either discouraged by inadequate communication and care or do not have sufficient resources to allow follow-up visits when their child's condition deteriorates or fails to improve. ${ }^{[29]}$

Better VR data is important as it allows for counting of all deaths (irrespective of where they occurred) and thus has the potential to provide accurate disaggregated data that are required for monitoring health outcomes and health service delivery at local levels. The VR system should provide these data at sub-national and local level. Although under- 5 mortality rates can be calculated using the number of registered births and VR deaths, incomplete reporting means that these figures are not sufficiently robust to allow for useful comparison at provincial and sub-national levels.

Recommendations for improving the availability of more accurate data include:

- Improvement in the quality of information on death certificates, especially regarding cause-of-death data. Improved training, better linkages to mortality audit processes and routine review of the accuracy and completeness of death notification forms by senior clinicians are all likely to contribute positively to this measure.

- Improved completeness of the VR. This requires two complementary strategies. The first relates to ensuring that death notification forms reach the Department of Home Affairs (and are then captured into the VR system). Most public-sector hospitals have Home Affairs offices; these offices currently focus primarily on birth registration but have the potential to play an important role in improving the completeness of VR. The second strategy relates to ensuring that all deaths that occur outside of healthcare facilities are reported. Both strategies would require closer collaboration between health facilities, the Department of Home Affairs and StatsSA at local, provincial and national levels.

- Better triangulation of data from various sources at all levels i.e. national, provincial and district levels. District Clinical Specialist
Teams will soon be required to complete a Quarterly Death Report, which will triangulate data on maternal, newborn and under-5 deaths from various sources. This will provide a mechanism for ensuring that DHIS data, mortality audit data and data from death notification forms are reconciled and triangulated. Particular attention should be placed on ensuring concordance between the number and age disaggregation of in-facility deaths reported through the DHIS and the VR system.

- Collaboration with StatsSA to ensure that censuses and other surveys collect relevant and accurate data on child deaths, and that these are triangulated with routine data sources.

Where available, data on child deaths from other sources such as surveillance sites, mortuary data and registries of children with chronic diseases should be integrated with routine data systems. Attention should be paid to identifying good practices with a view to ensuring that there is scale-up of these practices.

More research and/or investigation is required to explain and address the discrepancies in the number of newborn deaths reported through the different systems. There is also a need to better understand the extent of unreported community deaths.

\section{Conclusion}

Under-5 mortality rates in South Africa have fallen substantially in the past decade, and the SDG target of an under- 5 mortality rate of less than 25 per 1000 live births by 2030 is achievable. However, this will require ongoing declines in deaths from diarrhoea, pneumonia and HIV, as well as declines in deaths during the newborn period, and from emerging prominent causes of death (violence and injury, congenital disorders and non-communicable disorders). More attention will also need to be paid to understanding and addressing the high number of child deaths which occur outside of the healthcare system.

The country is not yet able to rely on VR data to generate under-5 mortality rates (without adjustment). While UN and RMS estimates allow us to track under-5 mortality at a national level, the accuracy and completeness of existing information systems, especially the VR system, will need to be improved to ensure that accurate data are available at provincial and district levels.

Acknowledgements. We thank Ms Koshen Moodley, who extracted the data from the Vital Registration database.

Author contributions. NM and LB conceptualised the article. NM compiled figures and tables. LB and NM with assistance from PB wrote the article. YA reviewed the article.

Funding. None.

Conflicts of interest. None.

1. United Nations General Assembly. Transforming our World: The 2030 Agenda for Sustainable Development. New York: UN, 2015. http://www.un.org/ga/search/view_doc.asp?symbol=A/ Development. New York: UN, 2015. http://
RES/70/1\&Lang=E (accessed 26 September 2017).

2. National Planning Commission (NPC). Our Future: Make it Work. National Development Plan 2030 Executive Summary. Pretoria: NPC, 2011. https://www.gov.za/sites/www.gov.za/files/Executive\%20 Summary-NDP\%202030\%20-\%20Our\%20future\%20-\%20make\%20it\%20work.pdf (accessed 1 June 2016). 3. World Health Organization. SDG 3: Ensure healthy lives and promote wellbeing for all at all ages. Geneva: WHO, 2015. http://www.who.int/sdg/targets/en/ (accessed 30 September 2017).

4. Lo S, Horton R. Everyone counts - so count everyone. Lancet 2015;386(10001):1313-1314. https://doi. org/10.1016/S0140-6736(15)60305-1

5. Shibuya K, Gilmour S. Civil registration as a means to promote human security. Lancet 2015;386(10001):e14-e15. https://doi.org/10.1016/S0140-6736(15)60765-6

6. UNICEF, WHO, World Bank, United National Population Division. Levels and trends in child mortality 2014. New York: UNICEF, 2014. https://www.unicef.org/media/files/Levels_and_Trends in_Child_Mortality_2014.pdf. (accessed 30 September 2017).

7. Bradshaw D, Pillay-van Wyk V, Laubscher R, et al. Cause of death statistics for South Africa: Challenges and possibilities. Cape Town: Burden of Disease Research Unit, 2010. http://www.mrc ac.za/bod/cause_death_statsSA.pdf (accessed 30 September 2017).

8. Dorrington RE, Bradshaw D, Laubscher R, Nannan N. Rapid mortality surveillance report 2014

Cape Town. South African Medical Research Council (SAMRC), 2015. www mrec ac 2014 RapidMortalitySurveillanceReport2014.pdf (accessed 30 September 2017). 
9. National Department of Health (NDoH). Health Data Advisory and Coordination Committee report. Pretoria: NDoH, 2012. http://www.health.gov.za/index.php/2014-03-17-09-09-38/reports/ category/100-2012rp\# (accessed 30 September 2017).

10. Alkema L, New JR. Global estimation of child mortality using a Bayesian B-spline bias-reduction method. Ann Appl Stat 2014;8(4):2122-2149. https://doi.org.10.1214/14-AOAS768.

11. Joubert J, Rao C, Bradshaw D, Vos T, Lopez AD. Evaluating the Quality of National Mortality Statistics from Civil Registration in South Africa, 1997-2007. PLOS ONE 2013;8(5):e64592. https://do org/10.1371/journal.pone. 0064592

12. Dorrington RE. Alternative South African Mid-year Estimates, 2013. CARe Monograph no 13. Cape Town: University of Cape Town, 2013. http://www.commerce.uct.ac.za/research_units/care/ monographs/monographs/mono13.pdf (accessed 15 November 2017).

13. National Department of Health, Statistics South Africa (StatsSA), SAMRC, ICF. South African Demographic and Health Survey 2016: Key Indicators. Pretoria: StatsSA, 2017. http://www.statssa. gov.za/publications/Report\%2003-00-09/Report\%2003-00-092016.pdf (accessed 30 September 2017)

14. Adewemimo A, Kalter HD, Perin J, Koffi AK, Quinley J, Black RE. Direct estimates of cause-specific mortality fractions and rates of under-five deaths in the northern and southern regions of Nigeria by verbal autopsy interview. PLOS ONE 2017;12(5):e0178129. https://doi.org/10.1371/journal. pone. 0178129

15. Liu L, Kalter H, Chu Y, et al. Understanding Misclassification between Neonatal Deaths and Stillbirths Empirical Evidence from Malawi. PLOS ONE 2016;11(12):e0168743. https://doi.org/10.1371/journal. pone. 0168743

16. Statistics South Africa. Census 2011 Statistical release - P0301.4. Pretoria: StatsSA, 2012. https://www. statssa.gov.za/publications/P03014/P030142011.pdf

17. National Department of Health. First Triennial Report of the Committee on Morbidity and Mortality in Children Under 5 Years (CoMMiC) 2008 - 2010. Pretoria: NDoH, 2011. http://www.health.gov.za/ index.php/2014-03-17-09-09-38/reports/category/101-2011rp?download=195:first-triennial-report-ofthe-committee-on-morbidity-and-mortality-in-children-under-five-years. (accessed 12 August 2017).

18. National Department of Health. District Health Management Information System (DHMIS) Policy. Pretoria: NDoH, 2011.https://www.idealclinic.org.za/docs/policies/District\%20Health\%20 Management\%20Information\%20System\%20Policy_2011.pdf (accessed 29 November 2017).

19. UNICEF. Under 5 mortality: Current Status and Progress. New York: UNICEF, 2017. https://data. UNICEF. Under 5 mortality: Current Status and Progress. New York: UNICEF, 2017.
unicef.org/topic/child-survival/under-five-mortality/ (accessed 30 September 2017).
20. Rhoda N, S Velaphi S, Gebhardt G, Kauchali S, Barron P. Reducing Neonatal Deaths in South Africa: Progress and challenges. S Afr Med J 2018;108(3 Suppl 1):S9-S16. https//doi/org/10. 7196/SAMJ.2018. v108i3.12804

21. UNICEF, WHO, World Bank, United Nations Population Division. Levels and Trends in Child Mortality 2015. New York: UNICEF, 2015. http://www.who.int/maternal_child_adolescent/ Mortality 2015. New York: UNICEF, 2015. http://www.who.int/1

22. Documents/levels_trends_child_mortality_2015/en/ (accessed 4 July 2016).
Dorington RE, Bradshaw D, Laubscher R, Nannan N. Rapid mortality surveillance report 2015. Cape Town: SAMRC, 2016. www.mrc.ac.za/bod/RapidMortalitySurveillanceReport2015.pdf (accessed 3 March 2017)

23. Nannan N, Dorrington R, Laubscher R, et al. Under-5 mortality statistics in South Africa: Shedding some light on the trends and causes 1997-2007. Cape Town: South African Medical Research Council, 2012. http://www.mrc.ac.za/bod/MortalityStatisticsSA.pdf (accessed 3 March 2017).

24. Bamford LJ, Barron P, Kauchali S, Dlamini NR. In-patient case fatality rates improvements in children under five: diarrhoeal disease, pneumonia and severe acute malnutrition. S Afr Med J 2018;108 (3 Suppl 1):S33-S37.

5. Nojilana B, Groenewald P, Bradshaw D, Reagon G. Quality of cause of death certification at an academic hospital in Cape Town, South Africa. S Afr Med J 2009;99(9):648-652.

26. Pillay-van Wyk V, Msemburi W, Laubscher R, et al. Mortality trends and differentials in South Africa from 1997 to 2012: Second National Burden of Disease Study. Lancet Glob Health 2016;4(9):e642-e653.
from 190 . https://doi.org/10.1016/S2214-109X(16)30113-9

27. Stephen CR. Saving Children 2012 - 2013: An Eighth Survey of Child Healthcare in South Africa. Pretoria: Tshepesa Press, 2016. http://www.childpip.org.za/images/stories/documents/saving children_2012-2013.pdf (accessed 26 September 2017).

28. Liu L, Oza S, Hogan D, et al. Global, regional, and national causes of under-5 mortality in 2000-15: An updated systematic analysis with implications for the Sustainable Development Goals. Lancet 2016;388(10063):2959-3086. https:// doi.org/10.1016/S0140-6736(16)31593-8

29. Sharkey AB, Chopra M, Jackson D, Winch PJ, Minkovitz CS. Pathways of care-seeking during fatal infant illnesses in under-resourced South African settings. Trans R Soc Trop Med Hyg 2012;106(2):110116. https://doi.org/10.1016/j.trstmh.2011.10.008

Accepted 11 December 2017 